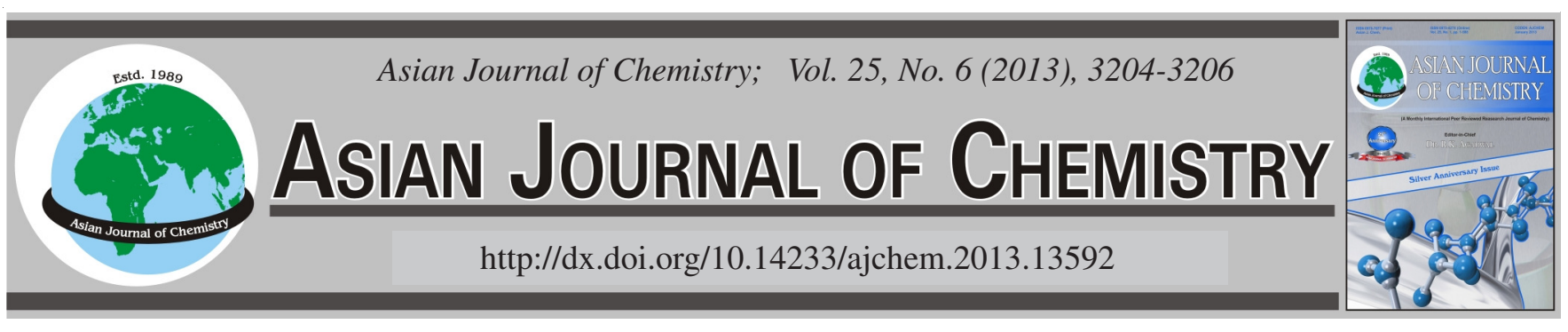

\title{
Volatile Oil Constituents of Vicia variabilis Frein \& Sint from Iran
}

M. KAZEMI ${ }^{*}$ and M. FADAEIAN

Department of Applied Chemistry, Qom Branch, Islamic Azad University, Qom, Iran

*Corresponding author: E-mail: smkazemit@yahoo.com

(Received: 14 February 2012;

Accepted: 14 December 2012)

AJC-12548

The water distillation of aerial parts of Vicia variabilis have been analyzed by a combination of GC-FID and GC/MS methods. Ninety compounds representing $92.7 \%$ of the total oil were characterized. The main components were hexahydrofarnesyl acetone $(6.6 \%), \beta$ ionone $(6.4 \%)$, myrtenol (3.7 \%), (Z)-phytol (3.3\%) and 1-octen-3-ol (3.1\%). Oxygenated monoterpenes constitute the major fraction of the oil $(26.3 \%)$, followed by aromatic compounds (11.9\%), sesquiterpenes oxygenated $(10.7 \%)$ and hydrocarbon aldehydes $(9.9 \%)$ while sesquiterpene hydrocarbons was not observed.

Key Words: Vicia variabilis, Papilionaceae, Essential oil composition, Hexahydrofarnesyl acetone, $\beta$-Ionone, Myrtenol, (Z)-phytol, 1Octen-3-ol.

\section{INTRODUCTION}

The genus Vicia L. (Papilionaceae) comprises 166 species in the world and its diversity centre is the Mediterranean region ${ }^{1}$. Fourty five or 46 species of Vicia has been reported from $\operatorname{Iran}^{2,3}$. Some researches from the genus Vicia have shown biological activity. The methanolic and ethanolic extracts of Vicia faba was tested for their antimicrobial, antioxidant and cytotoxic activities ${ }^{4}$. The methanolic extract of Vicia faba showed highest antimicrobial activity and high free radical scavenging activity but it had not remarkable cytotoxic activity against FL-cells. The hepatoprotective activity of flavonol glycosides from extract of the aerial parts of V. calcarata, was evaluated in a rat model with a liver injury induced by daily oral administration of $\mathrm{CCl}_{4}$ for four weeks ${ }^{5}$. The data obtained from this study revealed that the flavonol glycosides protect the rat liver from hepatic damage induced by $\mathrm{CCl}_{4}$ through inhibition of lipid peroxidation caused by $\mathrm{CCl}_{4}$ reactive free radicals. Also, antiherbivory defense of $V$. sativa and $V$. hirsuta with and without extrafloral nectarines was investigated ${ }^{6}$. Indirect ant defense of $V$. sativa was not consistently reliable. In addition, $V$. sativa was more vulnerable to attack by herbivores than $V$. hirsuta. The estimated total amount of sugars secreted by EFNs of $V$. sativa corresponded to $0.5 \%$ of total leaf biomass and $0.07 \%$ of total plant biomass, indicating a low investment to the production of extrafloral nectar. $V$. sativa plants grew more rapidly than $V$. hirsuta plants during the reproductive stage. The antioxidant activity of the polyphenols extracted from the seeds of 28 Vicia species collected in southern Spain was studied ${ }^{7}$. The highest specific polyphenols antioxidant activity was observed in the extracts from $V$. parviflora and $V$. tenuifolia. On the contrary, the highest total antioxidant activity was observed in $V$. sativa. The results showed that the Vicia species may represent a source of natural polyphenols with high antioxidant activity. The antimicrobial activity of the isolated essential oils of $V$. dadianorum was investigated $^{8}$ and it showed moderate antimicrobial and antifungal activities against Staphylococcus aureus, Enterococcus faecalis, Bacillus cereus, Mycobacterium smegmatis and Candida albicans. The genus Vicia has been studied chemically by some researchers for example tannin ${ }^{9}$, flavonoides ${ }^{10,11}$ and sesquiterpene ${ }^{12}$. Although, a few reports appear in the literature on Vicia essential oils ${ }^{8,13,14}$. To the best of our knowledge, no studies have been reported on the oil of $V$. variabilis, hence they decided to investigate the chemical compositions of this oil.

\section{EXPERIMENTAL}

The aerial parts of Vicia variabilis was collected during the flowering stage in Alamut area, province of Qazvin, Iran, in May 2010. A voucher specimen has been deposited at the Herbarium of the Research Institute of Forests and Rangelands (TARI), Tehran, Iran.

Isolation of the oil: The air-dried aerial parts Vicia variabilis of the plant (in the shade at room temperature, $154 \mathrm{~g}$ ) was subjected to water distillation using a Clevenger-type apparatus and extracted by diethyl ether for $3 \mathrm{~h}$. After decanting 
and drying over anhydrous sodium sulfate, the corresponding yellowish coloured oil was recovered in yields of $0.04 \% \mathrm{v} / \mathrm{w}$. The sample were stored in dark glass bottles in a freezer $\left(-5^{\circ} \mathrm{C}\right)$ until further use and analyze.

Gas chromatography-flame ionization detector analysis was performed on a Shimadzu 15A gas chromatograph equipped with a split/splitless (ratio 1:30), injector $\left(250{ }^{\circ} \mathrm{C}\right.$ ) and a flame ionization detector $\left(250^{\circ} \mathrm{C}\right) . \mathrm{N}_{2}$ was used as carrier gas $(1 \mathrm{~mL} / \mathrm{min})$ and the capillary column used was DB-5 (50 m $\times 0.2 \mathrm{~mm}$, film thickness $0.32 \mu \mathrm{m})$. The column temperature was kept at $60{ }^{\circ} \mathrm{C}$ for $3 \mathrm{~min}$ and then heated to $220^{\circ} \mathrm{C}$ with a $5{ }^{\circ} \mathrm{C} / \mathrm{min}$ rate and kept constant at $220^{\circ} \mathrm{C}$ for $5 \mathrm{~min}$. Relative percentage amounts were calculated from peak area using a Shimadzu C-R4A chromatopac without the use of correction factors.

Gas chromatography-mass spectroscopy analysis was performed using a Hewlett-Packard 5973 with a HP-5 MS column $(30 \mathrm{~m} \times 0.25 \mathrm{~mm}$, film thickness $0.25 \mu \mathrm{m})$. The column temperature was kept at $60{ }^{\circ} \mathrm{C}$ for $3 \mathrm{~min}$ and programmed to $220^{\circ} \mathrm{C}$ at a rate of $5{ }^{\circ} \mathrm{C} / \mathrm{min}$ and kept constant at $220^{\circ} \mathrm{C}$ for $5 \mathrm{~min}$. The flow rate of helium as carrier gas was ( $1 \mathrm{~mL} / \mathrm{min})$. MS were taken at $70 \mathrm{eV}$, mass range, 30 to $350 \mathrm{amu}$ and scan time 2 scans/sec.

Identification of components: The compounds were identified by comparison of their mass spectra with the Wiley library or with published mass spectra ${ }^{15}$. The identifications were confirmed by comparison of KI from HP-5MS column with those reported in the NIST liberary and the Pherobase database $^{16,17}$. The Kovats indices for all the components were determined according to the Van Den Dool method, using $n$-alkanes as standards ${ }^{18}$.

\section{RESULTS AND DISCUSSION}

The volatile constituents obtained from Vicia variabilis in the flowering stage are listed (Table-1). In this table, the percentage and kovats indices of the components are given. Ninety compounds were obtained that representing $92.7 \%$ of the total constituents in the essential oil. The main components were characterized by hexahydrofarnesyl acetone (6.6\%), $\beta$-ionone (6.4\%), myrtenol (3.7\%), (Z)-phytol $(3.3 \%)$ and 1-octen-3-ol (3.1\%). Oxygenated monoterpenes constitute the major fraction of the oil $(26.3 \%)$, followed by aromatic compounds (11.9\%), sesquiterpenes oxygenated $(10.7 \%)$ and hydrocarbon aldehydes $(9.9 \%)$ while sesquiterpene hydrocarbons was not observed.

\section{TABLE-1}

COMPOSITION OF Vicia variabilis ESSENTIAL OIL

\begin{tabular}{|c|c|c|c|c|}
\hline & Compound & $\mathrm{RI}^{\mathrm{a}}$ & $\mathrm{RI}^{\mathrm{b}}$ & $(\%)^{\mathrm{c}}$ \\
\hline 1 & (E)-2-Hexanal & 853 & 855 & 2.7 \\
\hline 2 & (E)-3-Hexen-1-ol & 858 & 860 & 2.0 \\
\hline 3 & $n$-Heptanal & 904 & 898 & 0.4 \\
\hline 4 & $\alpha$-Pinene & 937 & 939 & 1.7 \\
\hline 5 & Acetonyl acetone & 932 & 933 & 0.7 \\
\hline 6 & (E)-2-Heptenal & 956 & 960 & 0.3 \\
\hline 7 & Benzaldehyde & 957 & 961 & 0.7 \\
\hline 8 & Isoamyl propionate & 972 & 969 & 0.8 \\
\hline 9 & 1-Octen-3-ol & 978 & 979 & 3.1 \\
\hline 10 & 6-Methyl-5-hepten-2-one & 984 & 986 & 0.5 \\
\hline 11 & 2-Pentyl-furan & 989 & 994 & 0.9 \\
\hline
\end{tabular}

\begin{tabular}{|c|c|c|c|c|}
\hline & Compound & $\mathrm{RI}^{\mathrm{a}}$ & $\mathrm{RI}^{\mathrm{b}}$ & $(\%)^{\mathrm{c}}$ \\
\hline 12 & 2-(1-Pentenyl) furan & 998 & 1000 & 0.5 \\
\hline 13 & $n$-Octanal & 999 & 1001 & 0.4 \\
\hline 14 & $(E, E)$-2,4-Heptadienal & 1003 & 1010 & 0.9 \\
\hline 15 & Limonene & 1025 & 1031 & 1.1 \\
\hline 16 & 1,8-Cineole & 1033 & 1039 & 1.1 \\
\hline 17 & Benzeneacetaldehyde & 1037 & 1042 & 1.8 \\
\hline 18 & 2-Octenal & 1054 & 1056 & 0.4 \\
\hline 19 & $(E, Z)$-3,5-Octadien-2-one & 1066 & 1068 & 0.9 \\
\hline 20 & 1-Octanol & 1068 & 1068 & 0.7 \\
\hline 21 & $(E, E)$-3,5-Octadien-2-one & 1099 & 1107 & 1.0 \\
\hline 22 & Linalool & 1106 & 1112 & 1.0 \\
\hline 23 & $n$-Nonanal & 1108 & 1114 & 2.4 \\
\hline 24 & Phenethyl alcohol & 1118 & 1116 & 0.6 \\
\hline 25 & cis-p-Menth-2-en-1-ol & 1123 & 1122 & 0.7 \\
\hline 26 & trans-p-Menth-2-en-1-ol & 1142 & 1140 & 0.6 \\
\hline 27 & Camphor & 1146 & 1143 & 2.0 \\
\hline 28 & $(E, Z)-2,6-$ Nonadienal & 1158 & 1156 & 0.3 \\
\hline 29 & $p$-Menthan-3-one & 1168 & 1166 & 0.3 \\
\hline 30 & Borneol & 1171 & 1169 & 0.5 \\
\hline 31 & Terpinene-4-ol & 1177 & 1182 & 0.4 \\
\hline 32 & $\alpha$-Terpineol & 1185 & 1189 & 0.5 \\
\hline 33 & Myrtenol & 1199 & 1196 & 3.7 \\
\hline 34 & Decanal & 1207 & 1206 & 1.1 \\
\hline 35 & Safranal & 1209 & 1212 & 0.6 \\
\hline 36 & 2,5-Thiophenedicarboxaldehyde & 1224 & 1220 & 0.5 \\
\hline 37 & Piperitol & 1226 & 1223 & 0.7 \\
\hline 38 & $\beta$-Cyclocitral & 1228 & 1226 & 0.8 \\
\hline 39 & Nerol & 1224 & 1228 & 2.6 \\
\hline 40 & (Z)-Citral & 1235 & 1238 & 0.7 \\
\hline 41 & Geraniol & 1253 & 1255 & 1.7 \\
\hline 42 & $\beta$-Homocyclocitral & 1262 & 1261 & 0.2 \\
\hline 43 & (E)-Citral & 1265 & 1267 & 0.8 \\
\hline 44 & 3-Methyl dodecane & 1278 & 1270 & 0.5 \\
\hline 45 & Dehydroedilan IIA & 1287 & 1284 & 1.2 \\
\hline 46 & Dehydroedilan IA & 1291 & NR & 2.2 \\
\hline 47 & 2-Methoxy-4-vinyl phenol & 1309 & 1313 & 0.6 \\
\hline 48 & $(E, E)$-2,4-Decandienal & 1313 & 1317 & 0.5 \\
\hline 49 & Myrtenyl acetate & 1325 & 1327 & 1.4 \\
\hline 50 & Citronellyl acetate & 1356 & 1354 & 0.4 \\
\hline 51 & Neryl acetate & 1365 & 1362 & 0.5 \\
\hline 52 & $n$-Tetradecane & 1399 & 1400 & 0.4 \\
\hline 53 & Methyl eugenol & 1401 & 1401 & 0.3 \\
\hline 54 & 2-Methyl-5-(1,1,5-trimethyl) furan & 1447 & 1440 & 1.2 \\
\hline 55 & Geranyl acetone & 1454 & 1453 & 1.7 \\
\hline 56 & 3-Methyl tetradecane & 1465 & 1462 & 1.1 \\
\hline 57 & BHT-quinol & 1480 & 1473 & 0.4 \\
\hline 58 & $\beta$-Ionone & 1486 & 1485 & 6.4 \\
\hline 59 & Geranyl propionate & 1489 & 1486 & 0.5 \\
\hline 60 & 1-Pentadecene & 1495 & 1490 & 0.4 \\
\hline 61 & $n$-pentadecane & 1498 & 1500 & 0.7 \\
\hline 62 & 2,4-bis (1,1-dimethylethyl) phenol & 1512 & 1512 & 0.5 \\
\hline 63 & Dihydro-actinidiolide & 1525 & 1522 & 0.4 \\
\hline 64 & 7-Methyl pentacosane & 1545 & 1548 & 0.6 \\
\hline 65 & trans-Nerolidol & 1564 & 1564 & 0.3 \\
\hline 66 & cis-3-Hexenyl benzoate & 1571 & 1570 & 0.2 \\
\hline 67 & Spathulenol & 1582 & 1578 & 0.7 \\
\hline 68 & Caryophyllene oxide & 1589 & 1583 & 0.4 \\
\hline 69 & $n$-Hexadecane & 1589 & 1600 & 0.5 \\
\hline 70 & Miristaldehyde & 1610 & 1613 & 0.5 \\
\hline 71 & Bezophenone & 1628 & 1628 & 0.7 \\
\hline 72 & epi- $\alpha$-Muurolol & 1646 & 1642 & 0.3 \\
\hline 73 & $n$-Hexyl salicylate & 1678 & 1675 & 0.3 \\
\hline 74 & n-Octadecane & 1798 & 1800 & 0.3 \\
\hline 75 & Shiromool & 1812 & 1810 & 1.6 \\
\hline 76 & Hexahydrofarnesyl acetone & 1847 & 1845 & 6.6 \\
\hline
\end{tabular}




\begin{tabular}{|c|c|c|c|c|}
\hline & Compound & $\mathrm{RI}^{\mathrm{a}}$ & $\mathrm{RI}^{\mathrm{b}}$ & $(\%)^{\mathrm{c}}$ \\
\hline 77 & Diisobutyl phthalate & 1872 & 1874 & 1.9 \\
\hline 78 & $(E, E)$-Farnesyl acetone & 1922 & 1921 & 0.8 \\
\hline 79 & Methyl palmitate & 1930 & 1927 & 0.4 \\
\hline 80 & Palmitic acid & 1966 & 1964 & 1.5 \\
\hline 81 & Dibutyl phthalate & 1970 & 1968 & 1.3 \\
\hline 82 & $n$-Eicosane & 1999 & 2000 & 0.3 \\
\hline 83 & $n$-Heneicosane & 1198 & 2100 & 0.4 \\
\hline 84 & (Z)-Phytol & 2116 & 2114 & 3.3 \\
\hline 85 & Leinoleic acid & 2148 & 2146 & 0.2 \\
\hline 86 & $n$-Tricosane & 2298 & 2300 & 0.8 \\
\hline 87 & $n$-Pentocosane & 2498 & 2500 & 0.5 \\
\hline 88 & bis-(2-Ethylhexyl) phthalate & 2555 & 2550 & 0.3 \\
\hline 89 & $n$-Heptacosane & 2699 & 2700 & 0.8 \\
\hline \multirow[t]{17}{*}{90} & $n$-Octacosane & 2797 & 2900 & 0.6 \\
\hline & Group components & & & \\
\hline & Hydrocarbons & & & \\
\hline & Alkanes, alkenes & & & 7.9 \\
\hline & Alcohols & & & 5.8 \\
\hline & Aldehyde & & & 9.9 \\
\hline & Ketones & & & 3.1 \\
\hline & Terpenoids & & & \\
\hline & Monoterpene hydrocarbones & & & 2.8 \\
\hline & Oxygenated monoterpenes & & & 30.1 \\
\hline & Sesquiterpene hydrocarbones & & & 0.0 \\
\hline & Sesquiterpenes oxygenated & & & 10.7 \\
\hline & Diterpenoids & & & 3.3 \\
\hline & Aromatic compounds & & & 11.9 \\
\hline & Fatty acids and fatty acid esters & & & 2.9 \\
\hline & Other compounds & & & 4.3 \\
\hline & Total identified & & & 92.7 \\
\hline & $\begin{array}{l}\text { ats indices determined on a HP } \\
\text { ned from references, }{ }^{\text {CPercentag }} \\
\text { lalization, NR: Not reported }\end{array}$ & $\overline{\mathrm{um}}$ & vats & \\
\hline
\end{tabular}

In other research on Vicia genus, the volatile oil of flowers of $V$. faba was shown to be a complex mixture of some 27 identifiable compounds ${ }^{13}$. In addition to the ubiquitous mono and sesquiterpenes, the porous-polymer entrained volatiles included a diverse range of phenylpropenoids which together accounted for over $7 \%$ of the total. Cinnamyl alcohol was also found to be the most abundant free alcohol in the epicuticular wax of $V$. faba flowers. Two new classes of epicuticular wax esters consisting of saturated C16, C18, C20, C22 and C24 fatty acids esterified with the phenylpropenoid, cinnamyl alcohol and with the diterpene, phytol have been identified. In another report, the leaf volatile constituents of $V$. sativa $L$. have been studied using HS/PME-GC/MS and GC-FID ${ }^{14}$. Forty-three components, aliphatic hydrocarbons, alcohols, aldehydes and ketones, aromatic aldehydes, esters and alcohols, monoterpenes and sesquiterpenes were fully characterized by mass spectra, linear retention indices and injection of standards; the average composition as single components and classes of substances was reported. Leaf volatiles in $V$. sativa were characterized by a high amount of aldehydes, with the (Z)-2-hexenal the main component. In recent study, chemical composition of the essential oil of $V$. dadianorum have been isolated by hydro and microwave distillations (HD and
$\mathrm{MD})^{8}$. The compositions of the essential oils were characterized by GC-FID and GC/MS. A total of seventy-six and fifty-six compounds were identified, constituting over $90.9 \%$ and $80.1 \%$ of oil composition respectively. Sesquiterpene hydrocarbons were shown to be the main group of volatiles (HD: $26.2 \%$ and MD: $15.9 \%$ ). The major terpene constituent of the oils was $\gamma$-elemene (HD, $13.7 \%$ and MD, $8.4 \%$ ). In our research, some similar compounds such as fatty acid and esters, phytol and aldehydes were obtained.

\section{Conclusion}

In this research, 90 major and minor constituents of essential oils from V. variabilis were identified. The main components were characterized by hexahydrofarnesyl acetone, $\beta$-ionone, myrtenol, (Z)-phytol and 1-octen-3-ol. Oxygenated monoterpenes constitute the major fraction of the oil followed by aromatic compounds, sesquiterpenes oxygenated and hydrocarbon aldehydes. This result may be used in biological activities of $V$. variabilis. Considering to the major constituents, $V$ variabilis herb can be utilized as medicinal plant.

\section{ACKNOWLEDGEMENTS}

The authors are grateful to Dr. V. Mozaffarian, Research Institute of Forests and Rangelands, Tehran, Iran for botanical identification.

\section{REFERENCES}

1. N. Maxted, An Ecogeographical study of Vicia subgenus Vicia. IBPGR (International Plant Genetic Resources Institute, Systematic and Ecogeographic Studies in Crop Genepools), Rome, No. 8 (1995).

2. A. Chertkova-Zertova, in ed.: K.H. Rechinger, Flora Iranica and Papilionaceae-Vicieae, Vicia L. Academische Druck and Verlagsanstalt, Graz, Austria, No. 140, pp. 16-56 (1979).

3. V. Mozaffarian, A Dictionary of Iranian Plant Names, Farhang Moaser Publishers, Tehran, Iran (1996).

4. S. Akroum, D. Satta and K. Lalaoui, Eur. J. Sci. Res., 31, 289 (2009).

5. A.N. Singab, D.T. Youssef, E. Noaman and S. Kotb, Arch. Pharm. Res., 28, 791 (2005).

6. N. Katayama and N. Suzuki, Plant Ecol., 212, 743 (2010).

7. E. Pastor-Cavada, R. Juan, J.E. Pastor, M. Alaiz, J. Giron-Calle and J. Vioque, J. Food Biochem., 35, 1373 (2011).

8. N. Kahriman, B. Yayli, M. Yücel, S.A. Karaoglu and N. Yayli, Rec. Nat. Prod., 6, 49 (2012).

9. K. Kökten, A. Koçak, E. Bagci, M. Akçura1 and S. Çelik, Grasas Y Aceites, 61, 404 (2010)

10. P.F. Takachenko, I.I. Samokish, S.F. Dzhumyrko and V.A. Kompantsev, Chem. Nat. Compd., 10, 675 (1974).

11. E. Campeol, P.L. Cioni, G. Flamini, B. Rossi and R. Cremonini, Caryologia, 56, 365 (2003).

12. W. Dathe and G. Sembdner, Phytochemistry, 21, 1798 (1982).

13. D.W. Griffiths, G.W. Robertson, T. Shepherd and G. Ramsay, Phytochemistry, 52, 607 (1999).

14. V. Romeoa, A. Verzeraa, M. Ziinoa, C. Condursoa and G. Tripodia, J. Essent. Oil Res., 21, 33 (2009).

15. R.P. Adams Identification of Essential Oil Components by Gas Chromatography/Quadruple Mass Spectroscopy Allured Publishing Corp., Carol Stream, IL (2000).

16. http://webbook.nist.gov/

17. http://www.pherobase.com/database/kovats/kovats-index.php

18. H. Van Den Dool and P.D. Kratz, J. Chromatogr. A, 11, 463 (1963). 